\title{
Aplicabilidade da ecologia de saberes em saúde e ambiente e sua permeabilidade na produção acadêmica
}

\author{
The applicability of the ecology of knowledge in health \\ and environment and its permeability in the scientific literature
}

Leandro Luiz Giatti ${ }^{1}$

Rubens Landin ${ }^{1}$

Renata Ferraz de Toledo ${ }^{2}$
${ }^{1}$ Departamento de Saúde Ambiental, Faculdade de Saúde Pública, Universidade de São Paulo. Av. Dr. Arnaldo 715, Cerqueira Cesar. 01246-904 São Paulo SP Brasil.lgiatti@usp.br ${ }^{2}$ Fundação Escola de Sociologia e Política de São Paulo.

\begin{abstract}
A new epistemology makes it imperative for different knowledge to be incorporated in order to understand and interact with the complex problems that affect humanity, especially those associated with health and the environment. The study aims to explore the applicability of the ecology of knowledge in the midst of traditional scientific literature, focusing on participatory approaches to questions of health and the environment. The methodology involved a bibliographic review of an international scientific database, with the inclusion of 170 papers that were classified by their participatory approaches as: timely; multi-tool; and ongoing/cyclic. Although timely and multi-tool approaches may be effective in terms of aggregating popular knowledge, which is systematically marginalized by traditional science, it is in the ongoing/cyclic approaches that a higher level of potential dialogue is achieved, since it is possible to identify aspects inherent to more symmetric participation processes, with the prospect of empowerment of the social actors and legitimate incorporation of subjectivity and diversity. This corresponds to the premise that promoting global cognitive justice is indispensable for achieving global social justice.
\end{abstract}

Key words Community-based participatory research, Environmental health, Knowledge, attitudes, and practices in health
Resumo Uma nova epistemologia faz imperativo que distintos saberes sejam incorporados para compreender e interagir com os complexos problemas que afetam a humanidade, como aqueles que se associam à saúde e ambiente. O estudo objetiva explorar a aplicabilidade da ecologia de saberes em meio a publicações de artigos em veículos científicos tradicionais, focando abordagens participativas para questões de saúde e ambiente. A metodologia consiste de uma revisão bibliográfica em uma base internacional de amplitude pandisciplinar; com isso, 170 artigos incluídos neste estudo foram classificados por suas abordagens participativas como: pontual; multi-instrumentos; $e$ continuada/ciclica. Embora as abordagens pontuais e multi-instrumentos possam ser eficientes para possibilitar a incorporação de outros saberes, sistematicamente marginalizados pela ciência tradicional, é nas abordagens continuadas/cíclicas que se vislumbra maior potencial dialógico, pois se identificam aspectos inerentes à processos participativos mais simétricos, com perspectivas de empoderamento dos atores sociais e legítima incorporação de subjetividade e diversidade. Isto corresponde à premissa de que a promoção de uma justiça cognitiva global é indispensável para se obter uma justiça social global.

Palavras-chave Pesquisa participativa baseada na comunidade, Saúde ambiental, Conhecimentos, atitudes e prática em saúde 


\section{Introdução}

Há uma notável fronteira ainda prevalente delimitando a hegemonia do saber científico clássico, sendo esse um arranjo proveniente da aposta realizada no positivismo ao longo da modernidade. Nesse processo histórico constitui-se a opção pela objetividade, pelas certezas científicas e pela aversão a todo e qualquer indício de ambivalência. $\mathrm{Na}$ modernidade, apenas aquilo que for devidamente mensurável, classificável, preciso e objetivo pode lograr status de científico. Ou seja, pela escolha das certezas enunciadas dentro de uma estrutura rígida e objetiva de produção de conhecimento, de modo fluente, quando outras formas de saber foram sistematicamente marginalizadas ${ }^{1}$.

Popper, no entanto, colocou em evidência o fato de que, ao contrário do que se pensava, a cientificidade não se define pela certeza e sim pela incerteza, introduzindo a ideia do "falibilismo", em que as teorias científicas estão sujeitas à verificabilidade, expondo-as a uma eventual falseabilidade, a uma eventual observação discordante. Popper, com racionalidade, argumenta que nenhuma teoria científica pode ser provada para sempre ou resistir para sempre à falseabilidade, sendo racional na ciência o fato de que ela aceita ser testada, e algumas teorias científicas substituídas por outras que resistam melhor à falseabilidade ${ }^{2}$.

Assim, ao mesmo tempo em que crises de elevada magnitude e potencial de danos emergem na segunda metade do século vinte, contestamse, com isso, as certezas científicas e a perspectiva de que soluções técnico-científicas poderiam trazer soluções capazes de prover recursos, conforto e benesses necessárias para as populações humanas. Quanto a isso, podem-se destacar episódios como o acidente nuclear de Chernobyl, a síndrome da vaca louca, as mudanças climáticas globais e inúmeros acidentes industriais, bem como suas consequências ampliadas ${ }^{3-6}$. De fato, a partir da década de 1970, essa 'promessa' da modernidade se desvela contundentemente como inviável, da forma como os riscos e as vulnerabilidades vêm a migrar proporcional e conjuntamente com o aumento de intensidade da fluidez do capital ${ }^{5,7}$.

Com a evidenciação das incertezas e o reconhecimento dos riscos emerge a necessidade de se buscar novos modos de abordagem e de governança sobre fenômenos complexos. Com isso, algumas correntes de crítica científica ou propostas metodológicas vêm a se destacar como alternativas a hiperespecialização e a hermética estrutura de produção de saberes da ciência clássica.
Abordagens ou metodologias de pesquisa, como as denominadas por Community Based Participatory Research - CBPR, ganham cada vez mais reconhecimento, especialmente pelo envolvimento direto e colaborativo entre diferentes stakeholders (sujeitos da problemática investigada, pesquisadores e representantes de organizações/tomadores de decisão), em todas as etapas metodológicas, o que tem favorecido o desenvolvimento de intervenções bem sucedidas ${ }^{8,9}$.

Nesse contexto de insatisfação para com paradigmas e métodos clássicos de pesquisa e com a preocupação de ampliar o diálogo entre a ciência e a sociedade, outros movimentos/abordagens têm buscado novas formas dialéticas de interagir com atores sociais para compreender e agir sobre realidades complexas, compartilhando experiências e decisões. São exemplos: a Ciência Pós-Normal, em que as comunidades ampliadas de pares atuam na produção de conhecimento e gestão de incertezas ${ }^{10}$; a Abordagem Ecossistêmica em Saúde - também denominada Ecohealth baseada nos pilares da transdisciplinaridade, da participação e da equidade, onde a participação tem como objetivo chegar a um consenso e cooperação, não só dentro da comunidade, com os acadêmicos e com os tomadores de decisão, mas também entre eles ${ }^{11,12}$; a Pesquisa-ação em que, por meio de um sistema metodológico aberto de interação entre pesquisadores e atores sociais implicados na situação investigada, buscam-se respostas e soluções capazes de promover a transformação de representações e mobilizar os sujeitos para ações práticas ${ }^{13,14}$; e ainda, a Aprendizagem Social - aprender juntos para fazer juntos -, onde, a partir do reconhecimento pelos sujeitos e da explicitação de situações de conflito originárias de determinados problemas, desenvolve-se um trabalho cooperativo e de diálogo que favorecerá um processo de aprendizagem mútua com vistas à transformação de realidades complexas ${ }^{15}$.

As raízes das abordagens participativas com foco em situações de iniquidades vêm sendo disseminadas desde as décadas de 1940 e 1970 respectivamente por Kurt Lewin e por Paulo Freire. Lewin trabalhou com a pesquisa participativa combinando metodologias interativas por meio de um processo cíclico de planejamento, ação e interpretação, envolvendo minorias em situação de exclusão social, promovendo autoestima, equidade e uma perspectiva de cooperação ${ }^{16,17}$. Paulo Freire, por sua vez, realizou uma relevante contribuição para a educação dos oprimidos, em que seus postulados deram destaque e importância ao senso comum como parte do processo 
educativo, bem como em contextos de pesquisa. Dentro de uma prática libertadora, as propostas de Freire elucidaram a possibilidade de se construir novos conhecimentos de forma colaborativa para a resolução de problemas coletivos. Considera-se, ainda, que esses processos devem buscar romper com a convencional assimetria entre a hegemonia do saber científico clássico e a discriminação a que se submetem os outros saberes, especialmente os populares. Para Freire, a dialética natural dos conflitos em torno das desigualdades, que fazem o pano de fundo das questões sociais, precisa ser abordada sob uma perspectiva dialógica, ou seja, por meio de práticas que permitam trazer à tona os conhecimentos dos atores sociais de uma maneira justa e mais simétrica em relação ao saber dominante ${ }^{18}$.

Essa possibilidade de práticas de aprendizagem social sob perspectiva dialógica é consonante com o necessário rompimento das barreiras disciplinares e hiperespecializadas dos saberes científicos clássicos, podendo, portanto, indicar caminhos para o melhor equacionamento de questões que inquietam e ameaçam a humanida$\mathrm{de}^{19}$. De fato, a estrutura vigente de concentração e valorização do saber científico clássico se espelha também em uma cartografia de desigualdades sociais abissais.

O pensamento pós-abissal pode ser sintetizado como um aprender com o Sul usando uma epistemologia do Sul. Ele confronta a monocultura da ciência moderna com uma ecologia de saberes, na medida em que se funda no reconhecimento da pluralidade de conhecimentos heterogêneos (sendo um deles a ciência moderna) e em interações sustentáveis e dinâmicas entre eles sem comprometer sua autonomia. A ecologia de saberes se baseia na ideia de que o conhecimento é interconhecimento ${ }^{20}$.

Embora algumas décadas já tenham sido decorridas desde o início do desenvolvimento dessas práticas de pesquisas participativas, a questão da participação de atores sociais e a construção colaborativa de saberes, não apenas valorizando como também demandando o aporte de conhecimentos externos aos produzidos pelos pares acadêmicos, ainda deixa em aberto uma questão: de que maneira os saberes híbridos ou as experiências de pesquisa com participação de atores sociais vêm interferindo na produção científica dominante - o chamado mainstream science quanto aos dilemas de saúde e ambiente?

Nesse sentido, o objetivo deste estudo é explorar um panorama e reconhecer critérios da aplicabilidade da ecologia de saberes quanto a questões de saúde ambiental, fazendo desta uma perspectiva tangível. Em adição, considera-se que, mesmo havendo um significativo desenvolvimento epistemológico, crítico e ético, no que diz respeito a sobrelevar a importância de distintos saberes para lidar com os problemas complexos que afetam a humanidade, se espera identificar como resultados provenientes de abordagens participativas encontram, ou não, permeabilidade em clássicos canais de divulgação científica.

\section{Níveis de participação social em pesquisas}

A participação enquanto um "conceito" amplo envolve sentidos práticos, teóricos e institucionais, e é justamente essa multidimensionalidade ou polissemia que dificulta sua valoração ou o reconhecimento de seus efeitos - atribuídos ou desejáveis -, sejam estes de caráter pedagógico, psicológico, econômico e funcional, de integração e de racionalização ou de controle social. De qualquer maneira, deve-se destacar sua função educativa, no que diz respeito à construção da autoconfiança, autopercepção e pertencimento, gerando "círculos virtuosos" em que participação gera mais participação ${ }^{21}$. Esta estrutura de abordagem permite contribuir, conforme proposto por Lewin ${ }^{16}$, para legitimar a qualidade dos resultados do processo cíclico de planejamento, ação e interpretação, em que as investigações demandam intervenções que levam, por sua vez, a novas investigações e aprofundamento nos contextos em estudo, ao passo em que fortalecem os objetivos de empoderamento dos atores sociais.

Como elemento indispensável em abordagens ou metodologias participativas, considera-se que, no decorrer do seu desenvolvimento, poderá haver diferentes níveis de envolvimento e colaboração entre os participantes - pesquisadores, sujeitos da problemática investigada, tomadores de decisão -, os quais assumirão diferentes funções e/ou papéis complementares nas atividades de pesquisa e, se for o caso, de intervenção, com momentos de maior ou menor colaboração entre eles, o que não invalida o processo participativo, ${ }^{9,22,23}$.

Assim, ao investigar, refletir e agir, pesquisadores e sujeitos desenvolvem um processo de aprendizagem colaborativa e interativa, já que os resultados encontrados no decorrer do processo oferecerão novos ensinamentos a todos ${ }^{22}$. Temse, portanto, na participação, não apenas um elemento indispensável para abordagens ou metodologias dessa natureza, mas um determinante para a qualidade e sustentabilidade desse processo, no sentido de favorecer a produção colabo- 
rativa de saberes - aplicabilidade da ecologia de saberes. Esta conjuntura corrobora com o empoderamento e a tomada de decisões compartilhadas para o enfrentamento de situações de risco.

Por sua vez, reconhece-se que tanto a qualidade da participação como os diferentes níveis de envolvimento dos sujeitos são determinados, dentre outros aspectos, pela natureza dos instrumentos de pesquisa e intervenção que se aplicam, bem como pela forma como são utilizados. Neste texto, considerou-se que as intervenções participativas podem ser classificadas por sua dinâmica de aplicação de instrumentos em três categorias, conforme apresentado no Quadro 1. Ressalta-se, todavia, que a qualidade do processo participativo não irá lograr êxito quanto ao processo de empoderamento apenas no que diz respeito à quantidade de instrumentos, mas cabe observar que a combinação de distintos instrumentos participativos, com seus respectivos critérios de rigor, deve constituir o fluxo de interações necessárias para o melhor envolvimento entre atores sociais e pesquisadores ${ }^{13,24}$.

\section{Metodologia}

Este texto é produto de uma pesquisa de livre docência $^{25}$, realizada por meio de revisão bibliográ- fica sistematizada. A base de dados escolhida foi o sistema Web of Science, desenvolvido e mantido pelo Institute of Scientific Information/Thomsom Scientific, Philadelphia, EUA. Apesar de outras bases bibliográficas terem sido cogitadas para esse levantamento, como Scopus, Pubmed e Scielo, optou-se por Web of Science por ser uma base de dados bibliográficos genuinamente pandisciplinar ${ }^{26}$. As palavras-chave utilizadas em inglês correspondentes ao tema saúde e ambiente foram health e environment ou environmental, com adição de termos correspondentes à participação de atores sociais em pesquisas, como no caso do que se refere à pesquisa participativa, ou mesmo referente a conceitos ou metodologias que preconizam a participação. Desse modo, também foram utilizadas as palavras-chave participation ou participatory ou post-normal ou governance ou ecohealth. O período de seleção de artigos foi o correspondente ao oferecido pela base de dados, desde 1864 até 2012, todavia, as mais antigas publicações localizadas nesta busca datavam a partir de 1997.

A primeira triagem de artigos, apenas por palavras-chave, gerou resultado de 1.212 textos que foram subsequentemente filtrados a partir da leitura dos resumos com aplicação de critérios de refinamento: serem textos relacionados à participação de atores sociais ou intervenções parti-

Quadro 1. Classes de abordagens participativas quanto à dinâmica de aplicação de instrumentos.

\begin{tabular}{|c|l|}
\hline Classe & \multicolumn{1}{|c|}{ Caracterização } \\
\hline Pontual & $\begin{array}{l}\text { Abordagem participativa em que se verifica a aplicação de apenas um instrumento } \\
\text { participativo envolvendo atores sociais. Frequentemente remete a uma única } \\
\text { intervenção de modo transversal à cronologia das respectivas atividades de projeto de } \\
\text { pesquisa e intervenção. }\end{array}$ \\
\hline Multi-instrumentos & $\begin{array}{l}\text { Constitui-se em circunstancias em que se combinam distintos instrumentos, } \\
\text { porém sem caracterizar um processo de retroalimentação com ativa participação } \\
\text { dos atores sociais, inclusive na aplicação de instrumentos, análise de evidências e } \\
\text { redirecionamento metodológico do processo de pesquisa e intervenção. Ou seja, } \\
\text { apesar de haver uma dinamização da colaboração entre pesquisadores e atores } \\
\text { sociais, estes últimos bem como seus respectivos anseios não permitem, por exemplo, } \\
\text { modificações na estrutura e planejamento das atividades. }\end{array}$ \\
\hline Continuada/cíclica & $\begin{array}{l}\text { Caracteriza-se por aplicação de distintos instrumentos combinados e em cadeia de } \\
\text { retroalimentação, com elevada participação crítica dos sujeitos, inclusive provendo } \\
\text { questões a serem respondidas pelo processo de pesquisa, também caracterizando o } \\
\text { envolvimento colaborativo na dinâmica ou redelineamento metodológico. Nessa classe } \\
\text { de processo participativo é bem evidente uma dinâmica de retroalimentação, o que } \\
\text { deixa em destaque a correspondência com a perspectiva cíclica proposta por Lewin } \\
\text { (1946). }\end{array}$ \\
\hline
\end{tabular}


cipativas dialogando com questões socioambientais e de saúde. Quanto ao critério específico da participação de atores sociais, esta não deveria se resumir apenas a aquisição de informações, mas sim, a um processo interativo com os projetos de pesquisa e intervenção relatados. Em adição, critérios de exclusão também foram aplicados: artigos baseados unicamente em revisão bibliográfica e que não relatavam processo participativo aplicado; ou artigos em que os temas inerentes à participação social ou governança eram exclusivamente indicados na forma de uma recomendação ou conclusão de texto.

Após a aplicação desses critérios, a busca de textos completos permitiu a inclusão final de 170 artigos, que foram lidos integralmente e triados de acordo com as classes indicadas no Quadro 1, quanto a aplicação de instrumentos participativos como sendo uma abordagem: 1) pontual; 2) multi-instrumentos; e 3 ) continuada/cíclica.

\section{Um panorama da aplicação da ecologia de saberes no 'Mainstream Science'}

A distribuição temporal dos artigos selecionados (Gráfico 1) mostra o surgimento recente de publicações que cumprem com os critérios aplicados, bem como uma perspectiva de crescimento do número de publicações ao longo dos anos, especialmente a partir do ano de 2008. Por outro lado, é importante ressaltar que a produção de interesse deste tipo de pesquisa se coloca como tímida, considerando-se que a simples busca por artigos na mesma base bibliográfica, aplicandose apenas as palavras-chave respectivas à saúde e ambiente - 'health' and 'environment' or 'environmental' -, sem adição dos termos correspondentes a participação de atores sociais, gera mais de 100.000 resultados.

$\mathrm{Na}$ triagem a partir da leitura dos resumos houve, portanto, uma ampla redução de artigos. Isso ocorreu, em grande parte, pelo fato de que muitos artigos simplesmente indicavam a necessidade de algum processo participativo como recomendação para resolução de um dado problema em estudo. Para o termo governança, por exemplo, 513 artigos foram identificados via palavras-chave. Todavia, após a leitura dos resumos apenas 33 foram incluídos. Observa-se que, segundo Jacobi et al. ${ }^{27}$, o conceito de governança é relativamente recente, tendo sido mais utilizado na gestão de recursos naturais e problemas ambientais e, especialmente, na gestão da água a partir da década de 2000. A realização de pesquisas

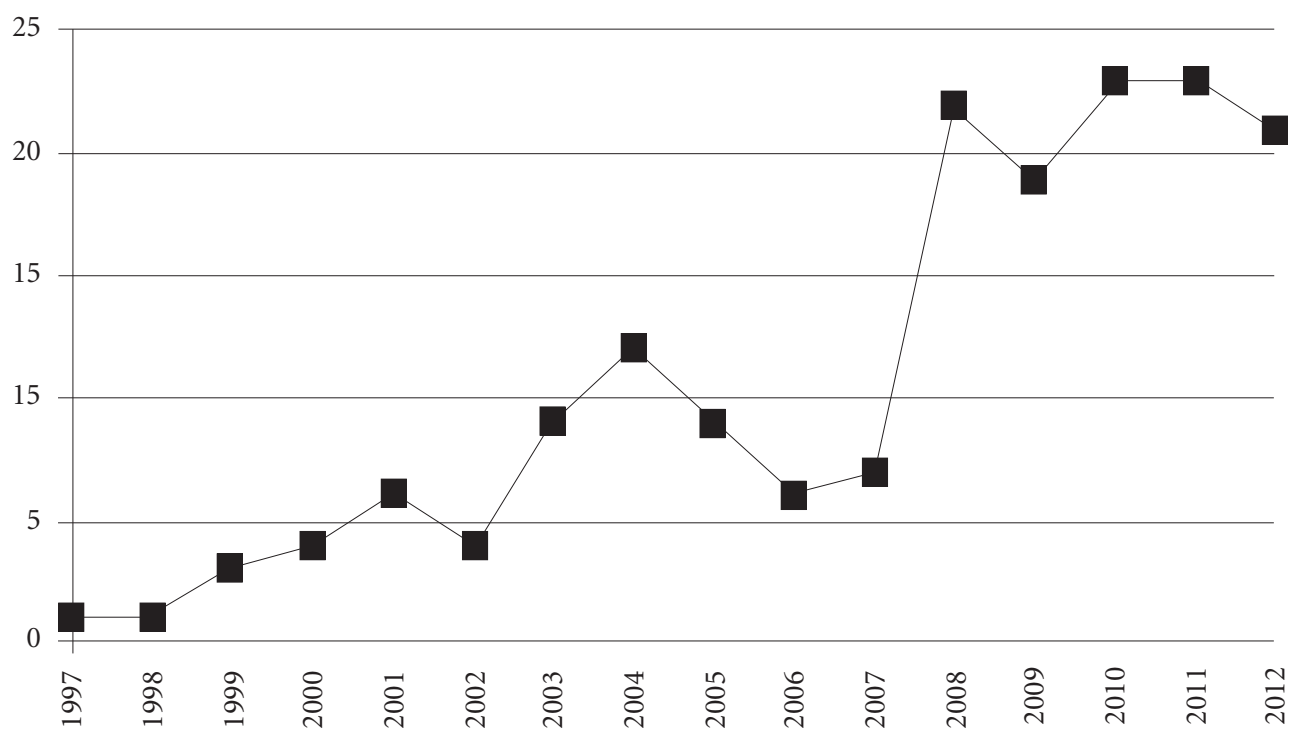

Gráfico 1. Evolução temporal por ano de publicação de artigos selecionados em revisão sistemática. 
e/ou intervenções sob orientação da governança pode ser considerada como um grande e atual desafio, principalmente pelo fato deste conceito ser razoavelmente recente e também em decorrência dos desafios da promoção de alianças e cooperação por meio da organização e participação de diversos atores envolvidos na gestão de situações ambientais, com suas formas de resistências, assimetrias sociais e impactos decorrentes.

Outra característica que merece destaque quanto aos artigos selecionados refere-se à dispersão dos mesmos em ampla diversidade de periódicos associados a distintas áreas de conhecimento, como ciências ambientais, saúde, educação, ciências sociais e geografia. Do total de artigos, 90 (53\%) estavam distribuídos em 29 periódicos, enquanto que os demais $80(47 \%)$ artigos encontravam-se cada qual publicado em um distinto periódico. Os periódicos com número mais expressivo de publicações foram: Health Education \& Behavior (9 artigos); Environmental Health Perspectives (8 artigos); Social Science \& Medicine (8 artigos); Health Promotion International (5 artigos); Journal of Urban Health (4 artigos); e Public Health Nursing (4 artigos). Isto leva a inferir que não há um espaço editorial definido para publicação do tema, embora seja distinguível haver uma tendência de produção no campo de pesquisas participativas com foco em questões de saúde e ambiente.

Quanto à aplicação da classificação referente às abordagens participativas descritas nos artigos selecionados, essa iniciativa se dirige aos desafios de se promover processos participativos que possam ter maior legitimidade quanto à promoção de uma ecologia de saberes, ao passo em que são incorporados outros saberes, que não apenas $o$ científico clássico, para compreender e intervir nos contextos socioambientais e de saúde. Nesse sentido, para se romper com a tradicional estrutura excludente, considera-se como dificuldade inicial o estabelecimento de confiança entre os sujeitos e pesquisadores, quando em processo de intervenção em comunidades socialmente desfavorecidas e culturalmente diferenciadas ${ }^{28}$. Além disso, há outros entraves, como: a desinformação e a falta de percepção para os problemas ambientais, de modo a dar suporte a maior envolvimento de atores sociais na gestão ambiental participativa ${ }^{29,30}$; e a necessidade de se aplicar, de modo combinado, diversos instrumentos participativos para promover a mobilização social para as questões de interesse ${ }^{31}$.

Não obstante, considera-se que há diferentes situações quanto à participação a partir do envolvimento dos sujeitos em processos de intervenção. Para List $^{23}$, esse processo tem níveis distintos, desde uma simples cooptação manipulativa, em que os sujeitos apenas interferem em diagnósticos e na compreensão de determinadas situações/problemas, até os níveis mais elevados de participação que seriam quando se efetivam o aprendizado colaborativo, a automobilização e o empoderamento. Ou seja, o maior anseio de um processo cíclico participativo deve ser o de permitir que os sujeitos adquiram sua autonomia para compreender os problemas em que estão inseridos, ter iniciativa para sua resolução ou mitigação, e para buscar soluções colaborativas, diálogo com gestores públicos, entre outras possibilidades de ações proativas.

Neste estudo não se tem o propósito de avaliar se as publicações selecionadas atingiram os níveis mais elevados de participação. Todavia, no sentido de contribuir para a aplicabilidade da ecologia de saberes, reconhecem-se diferenças entre uma abordagem com apenas um instrumento, de outra que adote um processo cíclico e continuado de planejamento, ações - aplicação de instrumentos participativos - e interpretação ${ }^{16}$. Com base nessa perspectiva, decidiu-se analisar os artigos selecionados e classificá-los em três categorias quanto aos instrumentos participativos dialógicos, sendo elas: pontual - 27 artigos, multi-instrumentos -67 artigos; e continuada/cíclica - 76 artigos (Gráfico 2).

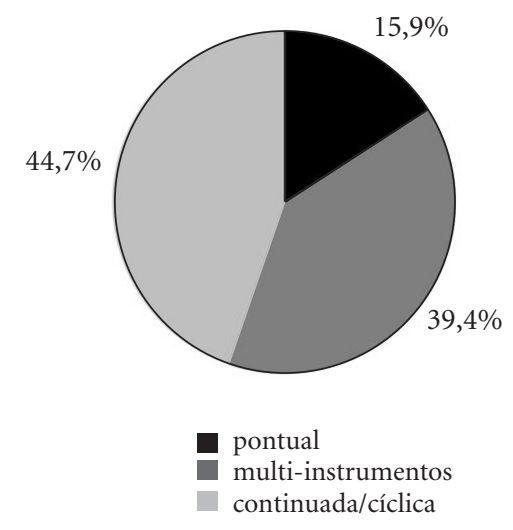

Gráfico 2. Distribuição de artigos selecionados em categorias segundo aplicação de instrumentos participativos.

Fonte: Elaborado pelos autores. 
Um primeiro caso a ilustrar uma abordagem pontual, ou seja, com aplicação de apenas um instrumento participativo, é o estudo de Nare et al. ${ }^{32}$ sobre a participação de sujeitos em comunidades rurais no Zimbabwe, onde, por meio da aplicação de grupos focais, os autores identificaram deficiências nos sistemas de monitoramento de qualidade de água, inclusive quanto à precária participação social nesse processo. O estudo também evidencia conhecimentos tradicionais inerentes à avaliação da qualidade da água e propõe que esses saberes sejam reconhecidos e incorporados pelos sistemas de informações públicos.

Holloman e Newman ${ }^{33}$ realizaram pesquisa participativa do tipo inquérito, aplicado a afro-americanos moradores de área costeira e com baixa renda (Virginia/EUA). O objeto de abordagem consiste do consumo de frutos do mar e riscos de contaminação, especialmente por mercúrio. $\mathrm{O}$ estudo envolveu mulheres negras moradoras locais na aplicação de entrevistas, tornando os sujeitos envolvidos na problemática enquanto pesquisadores, possibilitando, assim, que colaborassem ativamente com a análise de dados, discussões e conclusões, ou seja, todo esse processo de pesquisa foi diretamente mediado pelos saberes e valores dessas mulheres - atores sociais.

Como terceiro exemplo de aplicação pontual, Berbes-Blazquez ${ }^{34}$ relata processo de avaliação de serviços dos ecossistemas e bem-estar humano por meio de Photovoice desenvolvido em localidade rural, em uma bacia hidrográfica na Costa Rica, onde predomina a monocultura e processos de degradação do meio. Este instrumento de pesquisa participativa consiste da produção de imagens - fotografias - por parte dos atores sociais, que contextualizam determinado objeto e que, posteriormente, recebem a adição de narrativas capazes de descrever as percepções e representações sociais dos indivíduos sobre as questões em foco. A metodologia aplicada foi indicada como eficiente para incorporar a percepção/compreensão dos indivíduos da comunidade sobre os serviços dos ecossistemas.

Estudos com a aplicação de distintas ferramentas de caráter participativo, porém sem que os mesmos se configurassem em um processo de retroalimentação, foram classificados como abordagens multi-instrumentos. Ou seja, quando o desenho de pesquisa se apresentava estático, como algo já delimitado e planejado, sem a participação dos sujeitos em etapas de redelineamento metodológico. Esta é uma importante diferenciação, pois os estudos considerados de abordagem cíclica devem incorporar os sujeitos na perspectiva de continuidade no planejamento, na execução de ações e na identificação de evidências. Essas evidências, em processo cíclico, devem ter importância tanto no processo cognitivo como na execução de instrumentos ou ações subsequentes.

São exemplos de abordagens multi-instrumentos: uma aplicação de avaliação participativa rápida - Rapid Participatory Appraisal - em Belfast/Reino Unido, em que moradores de bairros socialmente desfavorecidos contribuíram com a indicação de problemas que não eram desvelados pelos indicadores tradicionais e, portanto, fugiam ao controle das políticas públicas. Essa pesquisa se constituiu da análise de dados oficiais sobre as áreas de estudo, aplicação de grupos focais e de questionários. Com a combinação de instrumentos de pesquisa participativa foi possível identificar, portanto, problemas como inerentes aos aspectos sociais, ambientais e relacionados aos equipamentos urbanos, todos determinantes do acesso dos indivíduos aos serviços de saúde ${ }^{35}$.

Derrick et al. ${ }^{36}$ relatam abordagem que objetivou sensibilizar comunidades estuarinas afro-americanas (Richmond/EUA) a se protegerem do excessivo consumo de peixes, com exposição à tóxicos, inclusive mercúrio, via cadeia alimentar. Para isso foram utilizados métodos de comunicação de riscos culturalmente adaptados e posterior inquérito sobre conhecimentos adquiridos e hábitos autorrelatados referentes à pesca.

Explorando abordagens que foram classificadas como continuadas/cíclicas, o artigo de Katsha e Watts ${ }^{37}$ constitui a primeira ilustração, reconhecida aqui como um modelo bem-sucedido de abordagem cíclica. Com foco no controle da esquistossomose em comunidades rurais no Egito, essa pesquisa partiu de técnicas qualitativas de enfoque antropológico, como observação participante, grupos focais e entrevistas, mesclando-as com monitoramento de qualidade de água e de presença de caramujos - hospedeiros intermediários e fundamentais na transmissão do agente patogênico -, e posterior processo de capacitação de agentes de saúde com a colaboração de sujeitos locais.

Ressalta-se que a principal característica da abordagem continuada/cíclica não é meramente a quantidade e diversificação de instrumentos; de fato, essa qualidade se consagra com o processo de retroalimentação - feedbacks - que dinamiza a pesquisa e permite que a participação dos sujeitos seja muito mais ativa e crítica. Os autores deste estudo assinalaram, por exemplo, que os saberes e interpretações dos sujeitos locais sobre 
a referida doença foram incorporados na capacitação desenvolvida e também no monitoramento realizado, pois contou com a participação integral destes atores sociais. Além disso, após o reconhecimento do importante papel das mulheres na estrutura social e em particular de sua possibilidade de contribuição na prevenção da doença, estas foram inseridas de modo estratégico em todas as etapas do processo participativo.

Quigley et al. ${ }^{38}$ apresentam relevante projeto de intervenção com foco na assistência de comunidades de indígenas norte-americanas presentes em distintos estados, as quais foram prejudicadas por exposições à radiação proveniente de testes nucleares realizados entre as décadas de $1950 \mathrm{e}$ 1960. Na abordagem, também trabalham com processo educativo de comunicação de riscos culturalmente adaptado, porém, diferentemente do artigo de Derrick et al. ${ }^{36}$, acima classificado como multinivel, Quigley et al..$^{38}$ avançam com o envolvimento dos sujeitos na condução técnica e comunitária de um estudo incorporando monitoramento ambiental, vigilância de doenças e uma pesquisa sobre a saúde da população local. Essa abordagem, segundo os autores, desenvolveu senso crítico e capacidade local, não só de interpretar as consequências e os problemas, como também possibilitou a autonomia necessária para dialogar, por exemplo, com atores governamentais em defesa de seus direitos por um ambiente livre de exposições às radiações nocivas. Essa possibilidade de defesa formal, por parte da própria comunidade e com o respaldo dos pesquisadores, é consonante com o princípio da advocacia (advocacy) do movimento de Promoção da Saúde ${ }^{39}$.

Um exitoso envolvimento de sujeitos assim relatado em um processo colaborativo de pesquisa vem sendo denominado de epidemiologia popular (popular epidemiology), como no caso do artigo de San-Sebastián e Hurtig ${ }^{40}$, na região amazônica do Equador, envolvendo organizações sociais de base local na definição de agenda de pesquisa desde a formulação de hipóteses até o tratamento e disseminação dos resultados. No caso, a intervenção é focada em amplo processo de degradação ambiental e de qualidade de vida decorrente de extensos derramamentos de petróleo. Como desdobramentos do processo de empoderamento, têm-se um posicionamento que faz frente à hegemonia corporativa da exploração do petróleo e interfere diretamente em uma política pública nacional de regulação do setor.

Abordagens pontuais ou multi-instrumentos podem ser eficazes quanto aos objetivos delimitados nas pesquisas de intervenção, sendo fre- quentemente associáveis a um corte transversal no tempo, em que, por meio das ações empreendidas, busca-se atingir os determinados objetivos mediante a complexidade das questões socioambientais e de saúde. A diferenciação de maior destaque, portanto, é que nas abordagens continuadas/cíclicas ocorre uma dinâmica de constantes interações entre os sujeitos e pesquisadores, entre saberes locais/tradicionais e saberes técnicos científicos, conjuntamente com a sequência de instrumentos interativos, configurando um processo de retroalimentação. Nesse aspecto de profunda colaboração, no qual os atores sociais passam inclusive a analisar dados, incorporar questões de seu interesse e, enfim, interferir no delineamento metodológico das pesquisas, é possível identificar o estabelecimento mais equilibrado entre pesquisadores e sujeitos, dentro do que se esperaria como uma abordagem dialógi$\mathrm{Ca}^{18}$, em que se abrandam as forças inerentes à assimetria entre ciência clássica e saber popular ou senso comum ${ }^{20}$.

Como afirmado anteriormente, não é o propósito avaliar a qualidade dos estudos de intervenção e sim, reconhecer critérios que os diferenciem pela forma de aplicação e combinação de instrumentos de pesquisa e intervenção. Todavia, é nas abordagens continuadas/cíclicas que se revelam possibilidades mais efetivas de empoderamento dos sujeitos envolvidos e a sustentabilidade das ações, esta última característica associada à autonomia, que habilita esses sujeitos sob forma organizacional e de apropriação de saberes e competências. Ou seja, novos problemas, que podem ser bastante diferenciados do foco das abordagens participativas, poderão ser enfrentados pelos atores sociais. Isto ocorre, portanto, sob uma perspectiva emancipatória.

Uma importante evidência desse tipo de processo reside na ocasião de desdobramentos de ações e intervenções locais em que os sujeitos ou suas representações legítimas, como organizações de base, passam a dialogar e interferir diretamente em políticas públicas, em um legítimo processo de baixo para cima - bottom-up -, conforme caracterizado por Minkler ${ }^{41}$, a partir de ampla experiência em pesquisas participativas de base comunitária - community-based participatory research - CBPR. Acrescenta-se ainda que sob a perspectiva de participação social em situações de governança de riscos, modelos associativos, na forma de movimentos sociais e associações, podem contribuir ativamente para a produção de importantes conhecimentos necessários à tomada de decisões ${ }^{42}$. 


\section{Considerações finais}

Para $\operatorname{Santos}^{20}$ não existe justiça social global sem justiça cognitiva global, o que significa dizer que o que se avizinha não pode ficar limitado à geração de alternativas, mas a tarefas mais complexas: requer um pensamento alternativo de alternativas. É preciso um novo pensar, considerando os abalos que o pensar global vem sofrendo principalmente desde a década de 1970. É preciso, portanto, um pensamento pós-abissal, metáfora que sintetiza um novo pensar que parte da ideia de que a diversidade do mundo é inesgotável. Com efeito, a ciência clássica não se constitui como o único saber, se não, como mais uma forma de conhecimento dentre muitas outras, que a propósito se colocam historicamente por seu potencial de aplicação. Para Ravetz ${ }^{10}$, romper com a estrutura hermética da produção de postulados a partir das comunidades de pares acadêmicos, incorporando um controle crítico com a participação de amplos atores sociais de interesse, constitui um processo de democratização da ciência.

Com isso, a ecologia de saberes surgiria como uma capacidade de indignação, capaz de fundamentar teorias e práticas novas, podendo ser inconformistas e até desestabilizadoras. Assenta-se na ideia pragmática da necessidade de se reavaliar intervenções e relações concretas na sociedade e na natureza que os diferentes conhecimentos proporcionam, estabelecendo hierarquias entre os saberes, que não sejam estáticas e opressoras, mas em conformidade com o contexto e à luz dos resultados concretos pretendidos. Não é, no entanto, uma ruptura dramática, mas um ligeiro desvio, de efeitos cumulativos que promoverão criativas e complexas combinações entre indivíduos e grupos sociais, com o poder de interagir positivamente com políticas públicas. Enquanto proposta, também não objetiva desvalorizar a importância do saber científico tradicional, mas sim, incorporar outros saberes de relevância para dialogar com fenômenos complexos que requerem decisões inerentes à subjetividade humana.

Morin $^{43}$ afirma que, ao confrontar com as incertezas, o ser humano é levado a uma nova consciência, uma nova aventura, em que é importante ser realista no sentido de compreender a incerteza do real, saber que há algo possível ainda invisível no real, demonstrando que é preciso saber interpretar a realidade antes de reconhecer onde está o realismo. As transformações, para o autor, se iniciam internamente e a partir de criações pontuais, quase microscópicas, em meio limitado a alguns indivíduos e surgem como des- vios em relação à normalidade. Se o desvio não for sufocado, ele pode, em condições favoráveis, paralisar a regulação que o freava ou reprimia, para, em seguida, proliferar de modo dinâmico, desenvolver-se, propagar-se e tornar-se eixo e tendência cada vez mais poderosa, produzindo uma nova normalidade.

Assim, por meio do diálogo de saberes se permite identificar e transcender fronteiras, formar um pensamento crítico, criativo e sintonizado com a necessidade de propor respostas para o futuro, capaz de analisar as complexas relações entre os processos naturais e sociais e de atuar no ambiente em uma perspectiva global, respeitando as diversidades socioculturais ${ }^{44}$. E é por meio da adição de complexidade provida pela subjetividade humana, que se propõe uma visão ampla e a necessidade de se estabelecer e/ou fortalecer o diálogo entre produção e aplicação de saberes estimulando constantes trocas e, especialmente, a possibilidade de apropriação da ciência por parte da sociedade.

Contudo, apesar de essas premissas em torno de uma lógica inclusiva para distintos saberes serem justificáveis, a produção elegível, sob os critérios adotados para participação social dentre publicações científicas sobre o tema saúde e ambiente, ainda parece modesta e, mesmo sob clara expansão, ainda demonstra estar muito ofuscada pela elevada produção dos chamados saberes científicos. Assim, a produção da ciência tradicional mantém a lógica de uma produção entre comunidades de pares acadêmicos, perpetuando, em grande parte, outros saberes em condição marginal. Embora seja plausível considerar o amplo respaldo epistemológico, crítico e ético em favor da ecologia de saberes, promover esse novo paradigma de relações mais simétricas e justas entre distintos saberes é algo que constitui um desafio em termos aplicáveis.

Por meio deste estudo, salienta-se o processo participativo envolvendo atores sociais na produção de saberes e na busca de intervenções para os complexos quadros que envolvem saúde e ambiente. A participação social figura como elemento chave para a aplicabilidade da ecologia de saberes. Mas há, contudo, várias maneiras de se promover processos participativos, neste texto tratadas por meio de classes quanto à combinação e abordagem por meio de instrumentos participativos. De fato, a classificação de abordagens participativas empreendida não se coloca meramente como uma perspectiva de qualificar ou desqualificar o envolvimento de atores sociais, mas sim, de mostrar que pode haver diferentes 
modos de se aplicar instrumentos e obter níveis de participação distintos para cada contexto de aplicação ou desafio que se pretende transpor. Por outro lado, também convém assinalar que, frequentemente, a produção acadêmica apenas trata a participação de atores sociais, bem como a inclusão de distintos saberes, de forma prescritiva, como uma recomendação, sem muito contribuir com a perspectiva de aplicabilidade desses pressupostos.

\section{Colaboradores}

LL Giatti, R Landin e RF Toledo participaram igualmente de todas as etapas de elaboração do artigo.

\section{Agradecimentos}

À FAPESP - Fundação de Amparo à Pesquisa do Estado de São Paulo. 


\section{Referências}

1. Bauman Z. Modernidade e ambivalência. Rio de Janeiro: Zahar; 1999.

2. Morin E. Ciência com consciência. 14a ed. Rio de Janeiro: Bertrand Brasil; 2010.

3. Beck U. La Sociedade del Riesgo Mundial: em busca de la seguridade. Barcelona: Paidós; 2008.

4. Hulme M. The appliance of science. The Guardian [internet]. 2007 [acessado 2014 maio 27];14(03). Available from: http://www.csrindonesia.com/data/articlesother /20070315105216-a.pdf

5. De Souza Porto MF, de Freitas CM. Vulnerability and industrial hazards in industrializing countries: an integrative approach. Futures 2003; 35(7):717-736.

6. De Marchi B, Ravetz JR. Risk management and governance: a post-normal science approach. Futures 1999; 31(7):743-757.

7. Harvey D. Condição Pós-Moderna: Uma pesquisa sobre as origens da mudança cultural. $18^{\mathrm{a}}$ ed. São Paulo: Loyola; 2009.

8. Wallerstein N, Duran B. Community-based participatory research contributions to intervention research: the intersection of science and practice to improve health equity. Am J Public Health 2010; 100(Supl. 1):S40-S46.

9. Cashman SB, Adeky S, Allen III AJ, Corburn J, Israel BA, Montaño J, Rafelito A, Rhodes SD, Swanston $S$, Wallerstein N, Eng E. The power and the promise: working with communities to analyze data, interpret findings, and get to outcomes. Am J Public Health 2008; 98(8):1407-1417

10. Ravetz J. The post-normal science of precaution. Futures 2004; 36(3):347-357.

11. Lebel J. Health: an ecosystem approach. Ottawa: IDRC; 2003.

12. Weihs M, Mertens F. Os desafios da geração do conhecimento em saúde ambiental: uma perspectiva ecossistêmica. Cien Saude Colet 2013; 18(5):1501-1510.

13. Thiollent M. Metodologia da Pesquisa-Ação. 18ª ed. São Paulo: Cortez; 2011.

14. Toledo RF, Jacobi PR. Pesquisa-ação e educação: compartilhando princípios na construção de conhecimentos e no fortalecimento comunitário para o enfrentamento de problemas. Educ Soc 2013; 34(122):155-173.

15. Pahl-Wostl C, Hare M. Processes of social learning in integrated resources management. J Community Appl Soc Psychol 2004; 14(3):193-206.

16. Lewin K. Action research and minority problems. J Soc Issues 1946; 2(4):34-46.

17. Adelman C. Kurt Lewin and the origins of action research. Educ Action Res 1993; 1(1):7-24.

18. Freire P. Pedagogia do Oprimido. Rio de Janeiro: Paz e Terra; 1987.

19. Santos BS. Um discurso sobre as ciências. 6a ed. São Paulo: Cortez; 2009.

20. Santos BS. Para além do pensamento abissal: das linhas globais a uma ecologia de saberes. Novos Estud-CEBRAP 2007; (79):71-94

21. Lavalle A, Vera EI. A trama da crítica democrática: da participação à Representação e à Accountability. Lua Nova 2011; 84:353-364.

22. Flicker S. Who benefits from community-based participatory research? A case study of the Positive Youth Project. Health Educ Behav 2008; 35(1):70-86.
23. List D. Action research cycles for multiple futures perspectives. Futures 2006; 38(6):673-684.

24. Toledo RF de, Giatti LL, Cutolo SA, Barreira LP, Pelicioni MCF. Um sistema metodológico aberto, dinâmico e legítimo na participação: Uma experiência multidisciplinar com pesquisa-ação em Iauaretê/AM. In: Toledo RF Jacobi PR, organizadores. A pesquisa-ação na interface da saúde, educação e ambiente: princípios, desafios e experiências interdisciplinares. São Paulo: Annablume; 2012. p. 115-131.

25. Giatti LL. Uma contribuição à ciência pós-normal: aplicações e desafios da ampliação da comunidade de pares em contextos socioambientais e de saúde [tese]. São Paulo: Universidade de São Paulo; 2013.

26. Jacso P. As we may search-Comparison of major features of the Web of Science, Scopus, and Google Scholar citation-based and citation-enhanced databases. Curr Sci-BANGALORE 2005; 89(9):1537.

27. Jacobi PR, Günther WMR, Giatti LL. Agenda 21 e Governança. Estud Av 2012; 26(74):331-340.

28. Christopher S, Watts V, McCormick AKHG, Young S. Building and maintaining trust in a community-based participatory research partnership. Am J Public Health 2008; 98(8):1398.

29. Giaretta JBZ. Participação social e gestão ambiental municipal no Brasil: desafios e condicionantes [dissertação]. São Paulo: Universidade de São Paulo; 2011.

30. Jacobi PR. Gestão democrática participativa no saneamento: conceitos e problematização. In: Brasil. Ministério das Cidades. Lei Nacional de Saneamento Básico: perspectivas para as politicas e gestão dos serviços públicos. Instrumentos das políticas e da gestão dos serviços públicos de saneamento básico. v. 1.Brasília: Ministério das Cidades; 2009. p. 103-113.

31. Toledo RF, Giatti LL, Pelicioni MCF. Mobilização Social em Saúde e Saneamento em Processo de Pesquisa-ação em uma Comunidade Indígena no Noroeste Amazônico. Saúde Soc 2012; 21(1):206-218.

32. Nare L, Love D, Hoko Z. Involvement of stakeholders in the water quality monitoring and surveillance system: The case of Mzingwane Catchment, Zimbabwe. Phys Chem Earth Parts ABC 2006; 31(15):707-712.

33. Holloman EL, Newman MC. A community-based assessment of seafood consumption along the lower James River, Virginia, USA: Potential sources of dietary mercury exposure. Environ Res 2010; 110(3):213-219.

34. Berbés-Blázquez M. A participatory assessment of ecosystem services and human wellbeing in rural Costa Rica using Photo-Voice. Environ Manage 2012; 49(4):862-875.

35. Lazenbatt A, Lynch U, O'Neill E. Revealing the hidden "troubles" in Northern Ireland: the role of participatory rapid appraisal. Health Educ Res 2001; 16(5):567578.

36. Derrick CG, Miller JS, Andrews JM. A Fish Consumption Study of Anglers in an At-Risk Community: A Community-Based Participatory Approach to Risk Reduction. Public Health Nurs 2008; 25(4):312-318.

37. Katsha $S$, Watts $S$. Schistosomiasis in two Nile delta villages: an anthropological perspective. Trop Med Int Health 1997; 2(9):846-854. 
38. Quigley D, Sanchez V, Handy D, Goble R, George P. Participatory research strategies in nuclear risk management for native communities. $J$ Health Commun 2000; 5(4):305-331.

39. Buss PM. Promoção da saúde e qualidade de vida. Cien Saude Colet 2000; 5(1):163-177.

40. San Sebastián M, Hurtig AK. Oil development and health in the Amazon basin of Ecuador: the popular epidemiology process. Soc Sci Med 2005; 60(4):799-807.

41. Minkler M. Linking science and policy through community-based participatory research to study and address health disparities. Am J Public Health 2010; 100(Supl. 1):S81-S87.

42. Giulio D, Marques G, Figueiredo BR, Ferreira L da C, Anjos D, Araújo JAS. Experiências brasileiras e o debate sobre comunicação e governança do risco em áreas contaminadas por chumbo. Cien Saude Colet 2012; 17(2):337-349.

43. Morin E. Os sete saberes necessários à educação do futuro. 2a ed. Brasília: Cortez; 2000.

44. Jacobi PR, Tristao M, Franco M. A função social da educação ambiental nas práticas colaborativas: participação e engajamento. Cad Cedes 2009; 29(77):63-79.

Artigo apresentado em 01/07/2014

Aprovado em 11/07/2014

Versão final apresentada em 12/07/2014 